\title{
INTERPOLATION METHOD FOR THE ANALYSIS OF THE FUNCTION OF MULTI-VARIABLES, AND ITS APPLICATIONS
}

(Trans. of JSCE March 1952)

Bennosuke Tanimoto, C.E. Member

\begin{abstract}
Synopsis The present report itself is a brief synopsis of my work concerning the interpolation during the last several years. It gives general expressions of interpolation formulas of various types, and applications to the mechanical cubature, biquadrature, etc. and to the difference equation. Seiches of two existing lakes, and a few torsion-problems are also given.
\end{abstract}

1. Various kinds of interpolation formulas of one variable have long since been proposed, such as Newton's, Stirling's, Bessel's, Gauss', Everett's, etc. They have served to the practical numerical analysis, that is, to the interpolation itself, to the mechanical quadrature, to the difference equation for ordinary differential equation, etc.

But little has been worked out, with regard to the interpolation of the function of two or more independent variables. Though a few interpolation formulas of two variables were given by Prof. S. NARUMI, STEFFENSON and other( ${ }^{12) 3)}$, the method of their derivation, from the practical stand-point, is very tedious and troublesome; and almost no further developments of the work have been made.

Interpolation formulas of the function of two or more independent variables can be obtained merely by means of repeated application of known interpolation formulas of one independent variable, their process being very simple and systematic. The notation or symbols proposed and exclusively used here would be the most convenient in comparison with those presented previously.

2. Interpolation formula of Newton type of many variables is written in the form

$$
f\left(x_{1}, x_{2}, \cdots x_{k}\right)=\sum_{r_{1}=0}^{n} \sum_{r_{2}=0}^{r_{1}} \ldots \sum_{r_{k}=0}^{r_{k}-1} \xi\left(u_{1}, r_{1}-r_{2}\right) \xi\left(u_{2}, r_{2}-1_{3}\right) \cdots \xi\left(u_{k}, r_{k}\right) \Delta{ }_{\left(r_{1}-r_{3}\right) x_{1}\left(r_{2}-r_{3}\right) x_{2} \cdots r_{k} x_{k}}^{r_{1}}(00 \cdots 0),
$$

where

$$
\begin{aligned}
& u_{1}=\frac{x_{1}-x_{10}}{h_{1}}, u_{2}=\frac{x_{2}-x_{20}}{h_{2}}, \cdots \cdots \cdots \cdots \cdot u_{k}=\frac{x_{k}-x_{k 0}}{h_{k}}, \\
& \xi(\theta, \alpha)=\frac{\theta(\theta-1)(\theta-2) \cdots(\theta-\overline{\alpha-1})}{L},\left(s_{1} s_{2} \cdots s_{k}\right)=f\left(x_{10}+s_{1} h_{1}, x_{20}+s_{2} h_{2}, \cdots s_{k 0}+s_{k} h_{k}\right),
\end{aligned}
$$

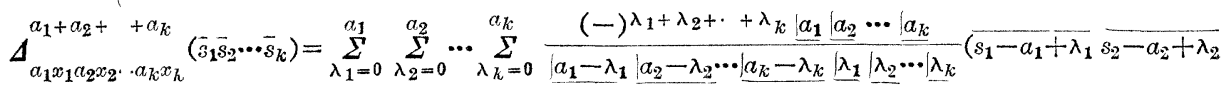

$$
\begin{aligned}
& \cdots \overline{s_{k}-a_{k}+\lambda_{k}} \text { ) }
\end{aligned}
$$

Also interpolation formula of Stirling type is written in the form

$$
\begin{aligned}
& f\left(x_{1}, x_{2}, \cdots x_{k}\right)=\sum_{r_{1}=0}^{n} \sum_{r_{2}=0}^{r_{1}} \cdots \sum_{r_{k}=0}^{r_{k}-1}\left[\phi\left(u_{1}, r_{1}-r_{2}\right) \rho\left(u_{2}, r_{2}-r_{3}\right) \cdots \phi\left(u_{k}, r_{k}\right) \stackrel{\left(2 r_{1}-2 r_{2}\right) x_{1}\left(2 r_{2}-2 r_{3}\right) x_{2} \quad 2 r k x k}{2 r_{1}}\right. \\
& \left(\overline{r_{1}-r_{2}} \overline{\left.r_{2}-r_{3} \cdots r_{k}\right)}\right. \\
& +\varphi\left(u_{1}, r_{1}-r_{2}\right) \varphi\left(u_{2}, r_{2}-r_{3}\right) \varphi\left(u_{3}, r_{3}-r_{4}\right) \cdots \varphi\left(u_{k}, r_{k}\right) \frac{1}{2} \Delta_{\left(2 r_{1}-2 r_{2}+1\right) x_{1}\left(2 r_{2}-2 r_{3}\right) x_{2}\left(2 r_{3}-2 r_{4}\right) \cdot 2 r_{k} x_{k k}}^{2 r_{1}+1} \\
& \left\{\left(\overline{r_{1}-r_{2}+1} \overline{r_{2}-r_{3}} \overline{r_{3}-r_{4} \cdots r_{k}}\right)+\left(\overline{r_{1}-r_{2}} r_{2}-r_{3} \overline{r_{3}-r_{4} \cdots r_{k}}\right)\right\}
\end{aligned}
$$




$$
\begin{aligned}
& +\varphi\left(u_{1}, r_{1}-r_{2}\right) \varphi\left(u_{2}, r_{2}-r_{3}\right) \varphi\left(u_{3}, r_{3}-r_{4}\right) \cdots \rho\left(u_{k}, r_{k}\right) \frac{1}{2} \Delta_{\left(2 r_{1}-2 r_{2}\right) x_{1}\left(2 r_{2}-2 r_{3}+1\right) x_{2}\left(2 r_{3}-2 r_{4}\right) x_{3} \cdots 2 r_{k} x_{k}}^{2 r_{1}} \\
& \left.\left\{\overline{\left(r_{1}-r_{2}\right.} \overline{r_{2}-r_{3}+1} \overline{r_{3}-r_{4}} \cdots \overline{r_{h}}\right)+\left(\overline{r_{1}-r_{2}} \overline{r_{2}-r_{3}} \overline{r_{3}-r_{4}} \cdots \overline{r_{k}}\right)\right\} \\
& +\phi\left(u_{1}, r_{1}-r_{2}\right) \phi\left(u_{2}, r_{2}-r_{3}\right) \cdots \psi\left(u_{k}, r_{k}\right) \frac{1}{2} \Delta_{\left(2 r_{1}-2 r_{2}\right) x_{1}\left(2 r_{2}-2 r_{3}\right) x_{2} \cdot\left(2 r_{k}+1\right) x_{k}}^{2 r_{1}+1} \\
& \left\{\left(\overline{r_{1}-r_{2}} \overline{r_{2}-r_{3} \cdots} \overline{r_{k}+1}\right)+\left(\overline{r_{1}-r_{2}} \overline{\left.r_{2}-r_{3} \cdots \cdot r_{k}\right)}\right\}\right. \\
& +\psi\left(u_{1}, r_{1}-r_{2}\right) \psi\left(u_{2}, r_{2}-r_{3}\right) \cdots \psi\left(u_{k}, r_{k}\right) \frac{1}{2^{k}} \Delta_{\left(2 r_{1}-2 r_{2}+1\right) x_{1}\left(2 r_{2}-2 r_{3}+1\right) x_{2}}^{2 r_{1}+k}\left(2 r_{k}+1\right) x_{k} \\
& \left\{\left(\overline{r_{1}-r_{2}+1} \overline{r_{2}-r_{3}+1} \cdots \overline{r_{h}+1}\right)+\left(\overline{r_{1}-r_{2}+1} \overline{r_{2}-r_{3}+1} \cdots \overline{r_{k}}\right)+\left(\overline{r_{1}-r_{2}+1} \overline{r_{2}-r_{3}+1}\right.\right. \\
& \left.\cdots r_{k-1}-r_{k} \overline{r_{h}+1}\right)+\cdots \cdots \cdots+\left(\overline{r_{1}-r_{2}} \overline{r_{2}-r_{3}+1} \overline{r_{3}-r_{4}+1} \cdot \overline{r_{k}+1}\right)+\left(\overline{r_{1}-r_{2}+1} \overline{r_{2}-r_{3}+1}\right. \\
& \left.\left.\cdots \overline{r_{k-1}-r_{k}} \overline{r_{k}}\right)+\overline{\left(r_{1}-r_{2}+1\right.} \overline{r_{2}-r_{3}+1} \times \overline{r_{k-2}-r_{k-1}} \overline{r_{k-1}-r_{k}+1} \overline{r_{k}}\right)+ \\
& \left.\left.+\left(\overline{r_{1}-r_{2}} \overline{r_{2}-r_{3}} \overline{r_{3}-r_{4}+1} \cdots \overline{r_{k}+1}\right)+\cdots \cdots \cdots+\left(\overline{r_{1}-r_{2}} \overline{r_{2}-r_{3} \cdots \cdot r_{h-1}-r_{k}} \overline{r_{k}}\right)\right\}\right] \text {, }
\end{aligned}
$$

where

$$
\begin{gathered}
\varphi(\theta, \alpha)=\frac{\theta^{2}\left(\theta^{2}-1\right)\left(\theta^{2}-4\right) \cdots\left(\theta^{2}-\overline{\alpha-1}^{2}\right)}{2 \alpha}, \quad \psi(\theta, \alpha)=\frac{\theta\left(\theta^{2}-1\right)\left(\theta^{2}-4\right) \cdots\left(\theta^{2}-\alpha^{2}\right)}{2 \alpha+1}, \\
\left(\bar{s}_{1} \bar{s}_{2} \cdots \bar{s}_{k}\right)=f\left(x_{10}-s_{1} h_{1}, x_{20}-s_{2} h_{2}, \cdots x_{k 0}-s_{h} h_{k}\right) .
\end{gathered}
$$

We can also obtain interpolation formulas of other types, and further those of mixed types, i.e., for instance, of Newton type in the $x_{1}$-direction, and of Stirling type in the $x_{z}$-direction, etc.

For instance, interpolation formula of Stirling type for the "function $f(x, y)$ is written down

$$
\begin{aligned}
& f(x, y)=\sum_{r=0}^{n} \sum_{s=0}^{r}\left[\varphi(u, r-s) \varphi(v, s) \Delta_{(2 r-2 s) x 2 s y}^{2 r} \overline{(r-s} \bar{s}\right)+\psi(u, r-s) \varphi(v, s) \frac{1}{2} \Delta_{(2 r-2 s+1) x 2 s y}^{2 r+1}\{(\overline{(r-s+1 \bar{s})} \\
& \left.+(\overline{r-s} s)\}+\varphi(u, r-s) \psi(v, s) \frac{1}{2} d_{(2 r-2 s) x(2 s+1) y}^{2 r+1}\{(r-s) \overline{s+1})+(r-s s)\right\}+\psi(u, r-s) \psi(v, s) \\
& \left.\left.\frac{1}{4} \Delta_{(2 r-2 s+1) r(2 s+1) y}^{2 r+2}\{\overline{(r-s+1} \overline{s+1})+(\overline{r-s+1} \bar{s})+(\overline{r-s} \overline{s+1})+(\overline{r-s} \bar{s})\right\}\right]
\end{aligned}
$$

3. From the formula just written we may obtain a general expression for the mechanical cubature of the definite integral $I=\int_{a}^{a \prime} \int_{b}^{b r} f(x, y) d x d y$. The resulting expression is

$$
\begin{aligned}
I=4 h k & \sum_{r=0,}^{n} \sum_{s=0}^{r} \frac{1}{2 r-2 s 2 s} \Delta^{2 r}(2 r-2 s) x 2 s y \overline{(r-s s)} \\
& \times \sum_{t=0}^{r-s-1}(-)^{t}-A_{t}(r-s-1) \\
2 r-2 s-2 t+1 & \nu^{2 r-2 s-2 t+1} \sum_{t=0}^{s-1}(-)^{t} \frac{A_{t}(s-1)}{2 s-2 t+1} \nu^{2 s-2 t+1,},
\end{aligned}
$$

where $a^{\prime}-a=2 \nu h, b^{\prime}-b=2 \nu k$, and

$$
\begin{aligned}
& A_{0}(\alpha)=1, \quad A_{1}(\alpha)=1^{2}+2^{2}+\cdots+\alpha^{2}, \quad A_{2}(\alpha)=1^{2}\left(2^{2}+3^{2}+\cdots+\alpha^{2}\right) \\
& +2^{2}\left(3^{2}+4^{2}+\cdots+\alpha^{2}\right)+\cdots+(\alpha-1)^{2} \alpha^{2}, \cdots \cdots \cdots A_{\alpha}(\alpha)=1^{2} 2^{2} \cdots \alpha^{2}
\end{aligned}
$$

The above result will also be applicable to the integral of the form

$I=\int_{0}^{\infty} \int_{0}^{\infty} f(x, y) d x d y$, which frequently takes place in theoretical investigation. The cited integral is sometimes of rapid convergence, and in such a case the work for the evaluation is not very laborious.

As the simplest case of the above expression, we take $\nu=1$ and retain terms in $4^{\circ}$. We then have $I=4 h k \frac{1}{6}\{2(00)+\Sigma(10)\}$, where, for brevity, $\Sigma(10)=(10)+(\overline{10})+(01)+(0 \overline{1})$. If in 
addition we retain the term in $\Delta^{4} 2 x 2 y$, we then have $I=4 h k^{\frac{1}{36}}\{16(00)+4 \Sigma(10)+\Sigma(11)\}$; this being frequently referred to the computation of the displacement tonnage of a vessel in naval engineering. The above two rules may reasonably be called Simpson's rules in two dimensions. More accurate rules can be written down, if required. Also, if we refer to the general expression derived from modified Bessel's interpolation formula, then the first approximation to the mechanical cubature becomes $\quad I=-\frac{h k}{4}\{(00)+(10)+(01)+(11)\}$. This is a rule that is sometimes used in civil engineering in computing the volume of cut or bank extending over a broad area.

Similar expressions for the mechanical cubature can be olstained from interpolation formulas of other types. Further, general expressions for the mechanical biquadrature can also be obtained from interpolation formulas for the function $f(x, y, z)$.

4. A method of differentiation of the function $f(x, y)$ has been devised by L. COLLATZ ${ }^{4}$ of Berlin University, and developed to a great extent by Prof. K. HIDAKA of Tokyo University, who has applied it successfully to various techrological problems.

The method is in assuming a square-like network in which lattice-point values of the function are involved, and in applying to it Taylor's expansion theorem for the function.

I have shown that the same results of the differentiation are obtained by term-byterm differentiation of Stirling's interpolation formula at the central lattice-point, which corresponds to a special case of the proposed differentiation. Difference equations for a linear partial differential equation at once follow from the above differentiation. First approximation to them affords, for instance, Liebmann's equation for the plane harmonic equation, and Wolf's equation for the plane biharmonic equation. Other series of difference equations are also derivable from interpolation formulas of other types. Further, similar calculation affords difference equations for partial differential equation of three variables.

5. As to the boundary-conditions of the difference equation method, little has been progressed. Only one criterion, so far as I am aware, has been given to the condition. $\frac{\partial f}{\partial x}=0$ for the rectangular boundary, which is known as the principle of image ${ }^{5}$. In fact, the chief obstacle against the difference equation method is in the way of expressing given boundary condition. A proposal to surmount this obstacle is given here, the method being in combining interpolation formula of Stirling type for the function $f(x, y)$ with its Taylor's expansion, and in annulling successive differences separately. For applying it to practical problems, a considerable amount of work is as yet needed, so that my present stage of the work does not enable me to apply this promising criterion to practical technological problems.

6. The problem of seiches of a lake or a bay is to find eigenvalues of the differential equation $\frac{\partial^{2} f}{\partial x^{2}}+\frac{\partial^{2} f}{\partial y^{2}}+\lambda f=0$, with the boundary condition $\frac{\partial f}{\partial \nu}=\alpha \frac{\partial f}{\partial x}+\beta \frac{\partial f}{\partial y}=0 ; \nu$ denoting the normal to the bounding curve of the lake, and $\alpha$, $\beta$ direction-cosines of the normal.

As to the method of treating the problem of seiches, a method has been proposed 
by the late I. TSUBOI ${ }^{6)}$. The principle of the method is in taking finite terms of particular solutions of the differential equation in the form of Bessel function, and in making these solutions satisfy the boundary-condition at finite points of the smoothed shore-line. By means of this method, seiches of several lakes in Japan have been treated by various investigators.

An alternative method for the problem is given here. The method is the direct application of the interpolation formula. Seiches of two existing lakes in Japan, Lake Tasawa in Akita Pref., and Lake Inawashiro in Fukushima Pref., were treated. As an approximation to the unknown function $f(x, y)$, I adopted by the foregoing interpolation formula of Stirling type,

$$
\begin{aligned}
f(x, y)=(00)+\frac{u}{2} & \Delta_{x}+\frac{v}{2} \Delta_{y}+\frac{u^{2}}{2} \Delta_{2 x}+\frac{u v}{4} \Delta_{x y}+\frac{v^{2}}{2} \Delta_{2 y} \\
& +\frac{u^{3}-u}{12} \Delta_{3 x}+\frac{u^{2} v}{4} \Delta_{2 x y}+\frac{u \eta^{2}}{4} \Delta_{x 2 y}+\frac{\eta^{3}-v}{12} \Delta_{s y},
\end{aligned}
$$

where, for brevity, $\Delta_{x}=\Delta_{x}\{(10)+(00)\}$ etc. This expression contains eleven unknown latticepoints. The differential equation was considered, for convenience' sake, at four points within the domain of $f(x, y)$. To take the boundary condition into consideration smooth out the shore-line of the lake, take the remaining seven points on the smoothed curve, and draw normals at these points to the curve. Then the direct substitution of these eleven conditions into the fundamental equations, derived from the cited interpolation formula, affords eleven simultaneous equations concerning the eleven unknowns, which do not contain constant terms, so that the determinant constructed by the coefficients must vanish. The equation so constructed will afford the eigen-values of the problem, from which the periods of the free oscillation are obtained.

The calculated periods of the seiches showed fair agreements with those due to the observations made by Prof. K. HONDA ${ }^{78)}$. That is to say, in the case of Lake Tasawa the calculated period of the seiches is $3 \mathrm{~min}$. $28 \mathrm{sec}$. for uninodal oscillation, while the corresponding period observed by Prof. HONDA is $3 \mathrm{~min} .30 \mathrm{sec}$; and in the case of Lake Inawashiro the respective periods of the seiches are $19 \mathrm{~min} .41 \mathrm{sec}$. and $19 \mathrm{~min} .07 \mathrm{sec}$. To obtain these results it was sufficient to work only for two or three days respectively, provided a hand-driven calculating machine is available. It is added that in the case of Lake Inawashiro, Prof. HONDA states that there are two distinct oscillations, one being of uninodal oscillation and the other of binodal one. But the latter oscillation would, in reality, be of trinodal one. This was seen in the process of my calculation, and was confirmed by the technical opinion of Prof. HIDAKA.

7. The problem of torsion of a prism is to solve the differential equation $\frac{\partial^{2} f}{\partial x^{2}}+\frac{\partial^{2} f}{\partial y^{2}}=0$, which holds at all points within any cross-section of the prism, with the boundary-condition $\frac{\partial f}{\partial \nu}=y \cos (x, \nu)-x \cos (y, \nu) ; \nu$ denoting the outward-drawn normal to the bounding curve. The torsional rigidity of the prism, $C$, say, is given by the integral $C=\mu \iint\left(x^{2}+y^{2}+x \frac{\partial f}{\partial y}-y \frac{\partial f}{\partial x}\right)$ $d x d y$, where the integration extends over the whole cross-sectional area of the prism; $\mu$ being the modulus of rigidity.

The problem of torsion has been fully discussed since the time of St. Venant ${ }^{9}$. But $\mathrm{n}$ the case when the bounding curve becomes a little intricate, the problem remains 
unsolved. In such a case the so-called analytical method of solution would seem almost inaccessible even for a highly trained analyst. In this regard, several semi-analytical or semi-numerical methods, such as Ritz's, Galerkin's, etc., have been proposed, and made a definite contribution to the problem.

The method here proposed is, as before, the direct application of interpolation formulas. The first trial of the method was done by the torsion problem of a square prism, that is, a prism whose cross-section is a square, by referring to the interpolation formula of Everett type. An approximation to the torsional rigidity, with a roughlymade calculation, resulted to $2.17 \mu$, while the corresponding rigorous value is known to be $2.25 \mu$; the error of my result being $-3.7 \%$. Such a degree of error would sometimes be of little significance in practical engineering.

The second work for the torsion was devoted to the evaluation of the torsional rigidity of an angle-shaped prism (cf. Fig.1), by referring to the interpolation formula of Newton type. It gave the value of $5.67 \mu$, while the prevailing formula in practical engineering affords in this case $2.33 \mu^{10)}$. It is to be noticed that a considerable amount of discrepancy has resulted, though the value here calculated seems not so accurate that the last digit of the result is not reliable.

Fig. 1

Fig. 2

The reliability of the calculated value will in general be justifiable, from the practical standpoint, by the convergence of the contribution of successive differences to the result.

The third trial of the torsion-problem was done by a cross-shaped prism (cf. Fig.2), by using the interpolation formula
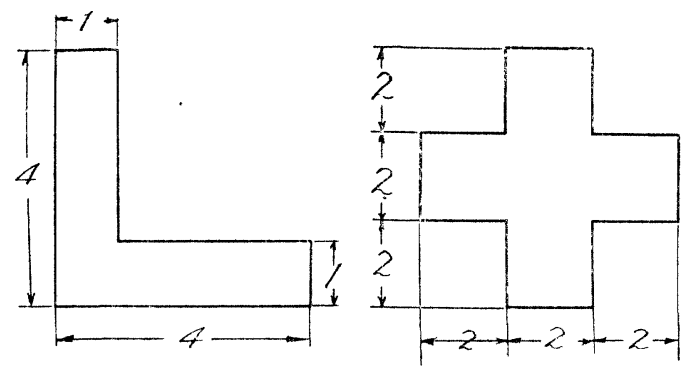
of modified Bessel type. Differences in the formula were taken up to the eighth order into account, and higher differences were neglected. The calculated torsional rigidity amounted to $30.35 \mu$, while the corresponding value referred to the prevailing formula affords $26.67 \mu$.

8. The work, as is clearly seen, is an entirely practical one, so that anyone may obtain, if necessary, his numerical result of a differential equation with which he is confronted, when he is only able to perform the ordinary calculation of numerals. I hope that the work may serve as a direct means connecting the partial differential equation with the practical numerical calculation. I desire also that detailed description of the work, with its further developments, may be published some other day.

ACKNOWLEDGMENT I should like to express my sincere thanks to Dr. Y. TANAKA, Member of Japan Academy and Honorable Professor of Tokyo University, for his valuable suggestions and useful advices. In fact, the present work was commenced by his advice. I am thankful also to Prof. M. HOMMA, Prof. G. NISHIMURA and Prof. K. HIDAKA of Tokyo University.

\section{REFERENCES}

1) The Tohoku Mathematica Journal, Sendai, Japan, Vol. 18 (1920), pp.309 321. 
2) Steffenson, Interpolation, 1943.

3) A. Amemiya, Suchikeisanhou, Kawade Shobou, 1943.

4) L. Collatz, Das Differenzenverfahren mit höherer Approximation für lineare Differentialgleichungen, Schriften des mathematischen Seminärs und des Instituts für angewandte Mathematik der Universität Berlin, Bd. 3, Heft 1, Berlin, 1935.

5) K. Hidaka, Suchisekibunhou, Iwanami, Vol. 2.

6) Loc. cit. 5).

7) Science Report of Tohoku University, First Series, Vol. 4, No. 1 (1915), pp.33 42.

8) Science Report of Tohoku University, First Series, Vol. 3, No. 1 (1914), pp.243 249.

9) Love, Elasticity, Chapa. XIV.

10) Cf., for instance, Kikai Kogaku Binran, Part I, p.308.

11) The same problem was treated by C. Runge; cf. loc. cit. 5). But I have had no chance to refer to his original paper.

(昭.26.10.19)

UDC 624.072 .233 .5

\title{
弾性支床上にある無限梁及び無限版の
}

\section{或る解法についで}

\section{正員 工学博士 喜 \\ 内 \\ 敏* \\ ON THE SOLUTION OF DIFFERENTIAL EQUATIONS, REPRESENTING THE VIBRATION OF INFINITE BEAMS AND PLATES SUPPORTED BY ELASTIC FOUNDATIONS}

(Trans. of JSCE March 1952)

Dr. Eng., Bin Kinai, C.E. Member

\begin{abstract}
Synopsis Making use of the same method as Arnold N. Lowan has adopted to the wave-motion for infinite domains, the author deduced directly from the differential equations, the formulae of vibrations of an infinite beam and plate supported by elastic foundation. Namely, the present writer applied the Laplace transformations to differential equations of vibration, and extended the domains infinitely with the aid of Fourier integrals; and furthermore, by adopting the corresponding inverse Laplace transformations, he obtained the results.

We can deduce the same results, by moving to the centre the origin of those formulae of vibrations which the author has had already deduced for finite domains, in the previous paper, and then by transforming them with the aid of Fourier integrals.
\end{abstract}

要旨 Arnold N. Lowan が無限領域の波動方程式の解法に用いた方法2゙を育用して弾性支床上にある梁及び 版の振動を示与微分方程式より，無限領域に抽るそれぞれの撓み振動の式を求めたるのである。即ち振動を示 す微分方程式に Laplace 変換の順变換をほどこし, Fourier integral を用いてこれを無限領域に公め, さらに Laplace 変換の逆変換を行つて解を求めた。な招, 有限長の梁及び版の場合については前に一般式を求めたが3 この式より座標原点を中央に移動し，Fourier integral を用いて同一の結果を求めることができる。

\section{I 弾性支床上にある無限梁}

(1) 公式の誘導 弾性支床上にある同一断面の梁の撓み振動の微分方程式は次式の如く示される。

$$
\begin{aligned}
& \frac{\partial^{4} y}{\partial x^{4}}+\frac{1}{a_{1}{ }^{2}}\left(\frac{\partial^{2} y}{\partial t^{2}}+2 k \frac{\partial y}{\partial t}+\lambda_{1}{ }^{2} y\right)=\frac{1}{a_{2}{ }^{2}} \phi(x, t) \\
&(-\infty<x<\ldots . . .
\end{aligned}
$$

ここに, $y \equiv y(x, t)$ : 梁の $x$ 点に怙ける $t$ 時の撓み, $\phi(x, t)$ : 梁の $x$ 点に作用する単位長さ当りの外力, $k$ : 梁の 減衰係数, な抢 $\lambda_{1}=\left(a_{1} / a_{2}\right) \sqrt{a}, a_{1}=\left(E J g / \gamma A_{0}\right)^{1 / 2}, a_{2}=V \overline{E J}, に し て \propto:$ 地船反力係数, $\gamma$ : 梁の単位体積の 